\title{
On Angrisani and Clavelli Synthetic Approaches to Problems of Fixed Points in Convex Metric Space
}

\author{
Ljiljana Gajić, ${ }^{1}$ Mila Stojaković, ${ }^{2}$ and Biljana Carićc \\ ${ }^{1}$ Department of Mathematics, Faculty of Science, University of Novi Sad, 21000 Novi Sad, Serbia \\ ${ }^{2}$ Department of Mathematics, Faculty of Technical Sciences, University of Novi Sad, 21000 Novi Sad, Serbia \\ Correspondence should be addressed to Mila Stojaković; stojakovic@sbb.rs
}

Received 30 March 2014; Accepted 22 June 2014; Published 7 July 2014

Academic Editor: Poom Kumam

Copyright (C) 2014 Ljiljana Gajić et al. This is an open access article distributed under the Creative Commons Attribution License, which permits unrestricted use, distribution, and reproduction in any medium, provided the original work is properly cited.

\begin{abstract}
The purpose of this paper is to prove some fixed point results for mapping without continuity condition on Takahashi convex metric space as an application of synthetic approaches to fixed point problems of Angrisani and Clavelli. Our results are generalizations in Banach space of fixed point results proved by Kirk and Saliga, 2000; Ahmed and Zeyada, 2010.
\end{abstract}

\section{Introduction and Preliminaries}

It is well-known that continuity is an ideal property, while in some applications the mapping under consideration may not be continuous, yet at the same time it may be "not very discontinuous."

In [1] Angrisani and Clavelli introduced regular-globalinf functions. Such functions satisfy a condition weaker than continuity, yet in many circumstances it is precisely the condition needed to assure either the uniqueness or compactness of the set of solutions in fixed point problems.

Definition 1. Function $F: M \rightarrow \mathbb{R}$, defined on topological space $M$, is regular-global-inf (r.g.i.) in $x \in M$ if $F(x)>$ $\inf _{M}(F)$ implies that there exist an $\varepsilon>0$ such that $\varepsilon<F(x)-$ $\inf _{M}(F)$ and a neighbourhood $N_{x}$ such that $F(y)>F(x)-\varepsilon$ for each $y \in N_{x}$. If this condition holds for each $x \in M$, then $F$ is said to be an r.g.i. on $M$.

An equivalent condition to be r.g.i. on metric space for $\inf _{M} f \neq-\infty$ is proved by Kirk and Saliga.

Proposition 2 (see [2]). Let $M$ be a metric space and $F$ : $M \rightarrow \mathbb{R}$. Then $F$ is an r.g.i. on $M$ if and only if, for any sequence $\left\{x_{n}\right\} \subset M$, the conditions

$$
\lim _{n \rightarrow \infty} F\left(x_{n}\right)=\inf _{M}(F), \quad \lim _{n \rightarrow \infty} x_{n}=x
$$

$\operatorname{imply} F(x)=\inf _{M}(F)$.
One of the basic results in [1] is the following one. (Here we use $\mu$ to denote the usual Kuratowski measure of noncompactness on metric space $(M, d)$ and $L_{c}:=\{x \in M \mid$ $F(x) \leq c\}$ for $F: M \rightarrow \mathbb{R}, c \in \mathbb{R}$.)

Theorem 3 (see [1]). Let $F: M \rightarrow \mathbb{R}$ be an r.g.i. defined on a complete metric space $M$. If $\lim _{c \rightarrow\left(\inf _{M}(F)\right)^{+}} \mu\left(L_{c}\right)=0$, then the set of global minimum points of $F$ is nonempty and compact.

Remark 4. The last theorem assures that if $T$ is a mapping of compact metric space into itself with $\inf _{M}(F)=0$, and if $F(x):=d(x, T x), x \in M$, is an r.g.i. on $M$, then the fixed point set of $T$ is nonempty and compact even when $T$ is discontinuous.

Example 5. Let $(X, d)$ be a complete metric space and $T$ : $X \rightarrow X$ a mapping such that, for some $q>1$ and all $x, y \in X$,

$$
\begin{gathered}
d(T x, T y) \leq q \max \{d(x, y), d(x, T x), d(y, T y), \\
d(x, T y), d(y, T x)\}
\end{gathered}
$$

(Ćirić quasi-contraction). Then $T$ is discontinuous and $F(x)=d(x, T x), x \in X$, is r.g.i. (see [1]).

Let $A$ be a bounded subset of metric space $M$. The Kuratowski measure of noncompactness $\mu(A)$ means the inf of numbers $\varepsilon$ such that $A$ can be covered by a finite number of sets with a diameter less than or equal to $\varepsilon$. With $\beta(A)$ we 
are going to denote the Hausdorff measure of noncompactness, where $\beta(A)$ is the infimum of numbers $\varepsilon$ such that $A$ can be covered by a finite number of balls of radii smaller than $\varepsilon$.

It is easy to prove that for $\alpha \in\{\mu, \beta\}$ and bounded subsets $A, B \subseteq M$

(1) $\alpha(A)=0 \Leftrightarrow A$ is totally bounded;

(2) $\alpha(\bar{A})=\alpha(A)$;

(3) $A \subset B \Rightarrow \alpha(A) \leq \alpha(B)$;

(4) $\alpha(A \cup B)=\max \{\alpha(A), \alpha(B)\}$.

Moreover, these two measures of noncompactness are equivalent in the sense that $\beta(A) \leq \mu(A) \leq 2 \beta(A)$ so $\lim _{n} \mu\left(A_{n}\right)=$ 0 if and only if $\lim _{n} \beta\left(A_{n}\right)=0$ (for any sequence $\left\{A_{n}\right\}$ of bounded subsets of $M$ ). The last property indicates that fixed point results are independent of choice of measure of noncompactness.

In Banach spaces this function has some additional properties connected with the linear structure. One of these is

$$
\alpha(\operatorname{conv} A)=\alpha(A)
$$

(conv $A$ is a convex hull of $A$-the intersection of all convex sets in $X$ containing $A$ ).

This property has a great importance in fixed point theory. In locally convex spaces this is always true, but when topological vector space is not locally convex it need not be true (see [3]).

In the absence of linear structure the concept of convexity can be introduced in an abstract form. In metric spaces at first it was done by Menger in 1928. In 1970 Takahashi [4] introduced a new concept of convexity in metric space.

Definition 6 (see [4]). Let $(X, d)$ be a metric space and $I$ a closed unit interval. A mapping $W: X \times X \times I \rightarrow X$ is said to be convex structure on $X$ if for all $x, y, u \in X, \lambda \in I$,

$$
d(u, W(x, y, \lambda)) \leq \lambda d(u, x)+(1-\lambda) d(u, y) .
$$

$X$ together with a convex structure is called a (Takahashi) convex metric space $(X, d, W)$ or abbreviated TCS.

Any convex subset of a normed space is a convex metric space with $W(x, y, \lambda)=\lambda x+(1-\lambda) y$.

Definition 7 (see [4]). Let $(X, d, W)$ be a TCS. A nonempty subset $K$ of $X$ is said to be convex if and only if $W(x, y, \lambda) \in K$ whenever $x, y \in K$ and $\lambda \in I$.

Proposition 8 (see [4]). Let $(X, d, W)$ be a TCS. If $x, y \in X$ and $\lambda \in I$, then
(a) $W(x, y, 1)=x$ and $W(x, y, 0)=y$;
(b) $W(x, x, \lambda)=x$;
(c) $d(x, W(x, y, \lambda))=(1-\lambda) d(x, y)$ and $d(y, W(x, y$, $\lambda))=\lambda d(x, y)$
(d) balls (either open or closed) in $X$ are convex;
(e) intersections of convex subsets of $X$ are convex.

For fixed $x, y \in X$ let $[x, y]=\{W(x, y, \lambda) \mid \lambda \in I\}$.

Definition 9. A TCS $(X, d, W)$ has property $(P)$ if for every $x_{1}, x_{2}, y_{1}, y_{2} \in X, \lambda \in I$,

$$
\begin{aligned}
& d\left(W\left(x_{1}, x_{2}, \lambda\right), W\left(y_{1}, y_{2}, \lambda\right)\right) \\
& \quad \leq \lambda d\left(x_{1}, y_{1}\right)+(1-\lambda) d\left(x_{2}, y_{2}\right) .
\end{aligned}
$$

Obviously in a normed space the last inequality is always satisfied.

Example 10 (see $[4])$. Let $(X, d)$ be a linear metric space with the following properties:

(1) $d(x, y)=d(x-y, 0)$, for all $x, y \in X$;

(2) $d(\lambda x+(1-\lambda) y, 0) \leq \lambda d(x, 0)+(1-\lambda) d(y, 0)$, for all $x, y \in X$ and $\lambda \in I$.

For $W(x, y, \lambda)=\lambda x+(1-\lambda) y, x, y \in X, \lambda \in I,(X, d, W)$ is a TCS with property $(P)$.

Remark 11. Property $(P)$ implies that convex structure $W$ is continuous at least in first two variables which gives that the closure of convex set is convex.

Definition 12. A TCS $(X, d, W)$ has property $(Q)$ if for any finite subset $A \subseteq X$ conv $A$ is a compact set.

Example 13 (see [4]). Let $K$ be a compact convex subset of Banach space and let $X$ be the set of all nonexpansive mappings on $K$ into itself. Define a metric on $X$ by $d(A, B)=$ $\sup _{x \in K}\|A x-B x\|, A, B \in X$ and $W: X \times X \times I \rightarrow X$ by $W(A, B, \lambda)(x)=\lambda A x+(1-\lambda) B x$, for $x \in K$ and $\lambda \in I$. Then $(X, d, W)$ is a compact TCS, so $X$ is with property $(Q)$. The property $(P)$ is also satisfied.

Talman in [5] introduced a new notion of convex structure for metric space based on Takahashi notion-the so called strong convex structure (SCS for short). In SCS condition $(Q)$ is always satisfied so it seems to be "natural."

Any TCS satisfying $(P)$ and $(Q)$ has the next important property.

Proposition 14 (see [5]). Let $(X, d, W)$ be a TCS with properties $(P)$ and $(Q)$. Then for any bounded subset $A \subseteq X$

$$
\alpha(\operatorname{conv} \mathrm{A})=\alpha(A) .
$$

Some, among the many studies concerning the fixed point theory in convex metric spaces, can be found in [6-13].

\section{Main Results}

Measures of noncompactness which arise in the study of fixed point theory usually involve the study of either condensing mappings or $k$-set contractions. Continuity is always implicit in the definitions of these classes of mappings. Kirk and Saliga [2] show that in many instances it suffices to replace the continuity assumption with the weaker r.g.i. condition. We are going to follow this idea in frame of TCS. 
Theorem 15. Let $(X, d, W)$ be a complete TCS with properties $(P)$ and $(Q), K$ a closed convex bounded subset of $X$, and $T$ : $K \rightarrow K$ a mapping satisfying the following:

(i) $\inf _{C}(F)=0$ for any nonempty closed convex $T$ invariant subset $C$ of $K$, where $F(x)=d(x, T x), x \in$ $K$

(ii) $\alpha(T(A))<\alpha(A)$ for all $A \subseteq K$ for which $\alpha(A)>0$;

(iii) $F$ is r.g.i. on $K$.

Then the fixed point set fix (T) of $T$ is nonempty and compact.

Proof. Choose a point $m \in K$. Let $\sigma$ denote the family of all closed convex subsets $A$ of $K$ for which $m \in A$ and $T(A) \subseteq A$. Since $K \in \sigma, \sigma \neq \emptyset$. Let

$$
B:=\bigcap_{A \in \sigma} A, \quad C:=\overline{\operatorname{conv}\{T(B) \cup\{m\}\}}
$$

Convex structure $W$ has property $(P)$ so $C$ is a convex set as a closure of convex set. We are going to prove that $B=C$.

Since $B$ is a closed convex set containing $T(B)$ and $\{m\}, C \subseteq B$. This implies that $T(C) \subseteq T(B) \subseteq C$ so $C \in \sigma$ and hence $B \subseteq C$. The last two statements clearly force $B=C$. that

Properties (1)-(4) of measure $\alpha$ and Proposition 14 imply

$$
\alpha(B)=\alpha \overline{(\operatorname{conv}\{T(B) \cup\{m\}\})}=\alpha(T(B)),
$$

so in view of (ii) $B$ must be compact.

Now, Proposition 2 ensures that $T$ has a fixed point on $B$ so $\operatorname{fix}(T)$ is nonempty. Condition (ii) implies that fix $(T)$ is totally bounded. Since $F$ is r.g.i. fix $(T)$ has to be closed. Finally, we conclude that $\operatorname{fix}(T)$ is compact.

The assumption $\inf _{K}(F)=0$ is strong, especially in the absence of conditions which at the same time imply continuity. So we are going to give some sufficient conditions which are easier to check and more suitable for application.

Let us recall some well-known definitions. A mapping $T$ : $K \rightarrow K$ is called nonexpansive if $d(T x, T y) \leq d(x, y)$, for all $x, y \in K$, and directionally nonexpansive if $d(T x, T y) \leq$ $d(x, y)$ for each $x \in K$ and $y \in[x, T x]$. If there exists $\alpha \in$ $(0,1)$ such that this inequality holds for $y=W(T x, x, \alpha)$, then we say that $T$ is uniformly locally directionally nonexpansive.

Proposition 16. Let $(X, d, W)$ be a complete TCS with property $(P), K$ a closed convex bounded subset of $X$, and $T$ : $K \rightarrow K$ a uniformly locally directionally nonexpansive. Let $T_{\alpha} x=W(T x, x, \alpha)$. For the fixed $x_{0} \in K$, sequences $\left\{x_{n}\right\}$ and $\left\{y_{n}\right\}$ are defined as follows:

$$
x_{n+1}=T_{\alpha} x_{n}, \quad y_{n}=T x_{n}, \quad n=0,1,2, \ldots
$$

Then for each $i, n \in \mathbb{N}$

$$
\begin{gathered}
d\left(y_{i+n}, x_{i}\right) \geq(1-\alpha)^{-n}\left(d\left(y_{i+n}, x_{i+n}\right)-d\left(y_{i}, x_{i}\right)\right) \\
+(1+n \alpha) d\left(y_{i}, x_{i}\right), \\
\lim _{n \rightarrow \infty} d\left(x_{n}, T x_{n}\right)=0 .
\end{gathered}
$$

Proof. We prove (10) by induction on $n$. For $n=0$ inequality (10) is trivial. Assume that (10) holds for given $n$ and all $i$.

In order to prove that (10) holds for $n+1$, we proceed as follows: replacing $i$ with $i+1$ in (10) yields

$$
\begin{aligned}
d\left(y_{i+n+1}, x_{i+1}\right) \geq & (1-\alpha)^{-n}\left(d\left(y_{i+n+1}, x_{i+n+1}\right)-d\left(y_{i+1}, x_{i+1}\right)\right) \\
& +(1+n \alpha) d\left(y_{i+1}, x_{i+1}\right) .
\end{aligned}
$$

Also

$$
\begin{aligned}
& d\left(y_{i+n+1}, x_{i+1}\right) \\
& \leq d\left(y_{i+n+1}, W\left(y_{i+n+1}, x_{i}, \alpha\right)\right) \\
& \quad+d\left(W\left(y_{i+n+1}, x_{i}, \alpha\right), W\left(T x_{i}, x_{i}, \alpha\right)\right) \\
& \leq(1-\alpha) d\left(y_{i+n+1}, x_{i}\right)+\alpha d\left(y_{i+n+1}, T x_{i}\right) \\
& \leq(1-\alpha) d\left(y_{i+n+1}, x_{i}\right)+\alpha \sum_{k=0}^{n} d\left(T x_{i+k+1}, T x_{i+k}\right) \\
& \leq(1-\alpha) d\left(y_{i+n+1}, x_{i}\right)+\alpha \sum_{k=0}^{n} d\left(x_{i+k+1}, x_{i+k}\right)
\end{aligned}
$$

since $x_{i+k+1}=W\left(T x_{i+k}, x_{i+k}, \alpha\right)$ and $T$ is uniformly locally directionally nonexpansive. Combining (12) and (13)

$$
\begin{aligned}
& d\left(y_{i+n+1}, x_{i}\right) \\
& \geq(1-\alpha)^{-(n+1)}\left(d\left(y_{i+n+1}, x_{i+n+1}\right)-d\left(y_{i+1}, x_{i+1}\right)\right) \\
& \quad+(1-\alpha)^{-1}(1+n \alpha) d\left(y_{i+1}, x_{i+1}\right) \\
& \quad-\alpha(1-\alpha)^{-1} \sum_{k=0}^{n} d\left(x_{k+i+1}, x_{k+i}\right)
\end{aligned}
$$

By Proposition 8 (c),

$$
\begin{aligned}
d\left(x_{k+i+1}, x_{k+i}\right) & =d\left(W\left(T x_{k+i}, x_{k+i}, \alpha\right), x_{k+i}\right) \\
& =\alpha d\left(y_{k+i}, x_{k+i}\right)
\end{aligned}
$$

so

$$
\begin{aligned}
& d\left(y_{i+n+1}, x_{i}\right) \\
& \geq(1-\alpha)^{-(n+1)}\left(d\left(y_{i+n+1}, x_{i+n+1}\right)-d\left(y_{i+1}, x_{i+1}\right)\right) \\
& \quad+(1-\alpha)^{-1}(1+n \alpha) d\left(y_{i+1}, x_{i+1}\right) \\
& \quad-\alpha^{2}(1-\alpha)^{-1} \sum_{k=0}^{n} d\left(y_{k+i}, x_{k+i}\right) .
\end{aligned}
$$


On the other hand,

$$
\begin{aligned}
d\left(y_{n}, x_{n}\right) & =d\left(T x_{n}, W\left(T x_{n-1}, x_{n-1}, \alpha\right)\right) \\
& \leq d\left(T x_{n}, T x_{n-1}\right)+d\left(T x_{n-1}, W\left(T x_{n-1}, x_{n-1}, \alpha\right)\right) \\
& \leq d\left(x_{n}, x_{n-1}\right)+(1-\alpha) d\left(T x_{n-1}, x_{n-1}\right) \\
& =\alpha d\left(y_{n-1}, x_{n-1}\right)+(1-\alpha) d\left(y_{n-1}, x_{n-1}\right) \\
& =d\left(y_{n-1}, x_{n-1}\right)
\end{aligned}
$$

for any $n \in \mathbb{N}$, meaning that $\left\{d\left(y_{n}, x_{n}\right)\right\}$ is a decreasing sequence. that

Now, using inequality $(1+n \alpha)-(1-\alpha)^{-n} \leq 0$, we have

$$
\begin{aligned}
& d\left(y_{i+n+1}, x_{i}\right) \\
& \geq(1-\alpha)^{-(n+1)}\left(d\left(y_{i+n+1}, x_{i+n+1}\right)-d\left(y_{i+1}, x_{i+1}\right)\right) \\
&+(1-\alpha)^{-1}(1+n \alpha) d\left(y_{i+1}, x_{i+1}\right) \\
&-\alpha^{2}(1-\alpha)^{-1}(n+1) d\left(y_{i}, x_{i}\right) \\
&=(1-\alpha)^{-(n+1)}\left(d\left(y_{i+n+1}, x_{i+n+1}\right)-d\left(y_{i}, x_{i}\right)\right) \\
&+\left((1-\alpha)^{-1}(1+n \alpha)-(1-\alpha)^{-(n+1)}\right) d\left(y_{i+1}, x_{i+1}\right) \\
&+\left((1-\alpha)^{-(n+1)}-\alpha^{2}(1-\alpha)^{-1}(n+1)\right) d\left(y_{i}, x_{i}\right) \\
& \geq(1-\alpha)^{-(n+1)}\left(d\left(y_{i+n+1}, x_{i+n+1}\right)-d\left(y_{i}, x_{i}\right)\right) \\
&+\left((1-\alpha)^{-1}(1+n \alpha)-(1-\alpha)^{-(n+1)}\right) d\left(y_{i}, x_{i}\right) \\
&+\left((1-\alpha)^{-(n+1)}-\alpha^{2}(1-\alpha)^{-1}(n+1)\right) d\left(y_{i}, x_{i}\right) \\
&=(1-\alpha)^{-(n+1)}\left(d\left(y_{i+n+1}, x_{i+n+1}\right)-d\left(y_{i}, x_{i}\right)\right) \\
&+(1+(n+1) \alpha) d\left(y_{i}, x_{i}\right) .
\end{aligned}
$$

Thus (10) holds for $n+1$, completing the proof of inequality.

Further, the sequence $\left\{d\left(y_{n}, x_{n}\right)\right\}$ is decreasing, so there exists $\lim _{n \rightarrow \infty} d\left(y_{n}, x_{n}\right)=r \geq 0$. Let us suppose that $r>0$. Select positive integer $n_{0} \geq d /(r \cdot \alpha), d=\operatorname{diam} K$, and $\varepsilon>0$, satisfying $\varepsilon(1-\alpha)^{-n_{0}}<r$. Now choose positive integer $k$ such that

$$
0 \leq d\left(y_{k}, x_{k}\right)-d\left(y_{k+n_{0}}, x_{k+n_{0}}\right)<\varepsilon
$$

Using (10), we obtain

$$
\begin{aligned}
d+r & \leq r\left(\alpha n_{0}+1\right) \leq\left(\alpha n_{0}+1\right) d\left(y_{k}, x_{k}\right) \\
& \leq d\left(y_{k+n_{0}}, x_{k}\right)+\varepsilon(1-\alpha)^{-n_{0}}<d+r .
\end{aligned}
$$

By the last contradiction we conclude that $r=0$ and $\lim _{n \rightarrow \infty} d\left(y_{n}, x_{n}\right)=\lim _{n \rightarrow \infty} d\left(T x_{n}, x_{n}\right)=0$ what we had to prove.
Remark 17. This statement is a generalization of Lemma 9.4 from [14].

Combining the last result with Theorem 15 we have the following consequence.

Corollary 18. Let $K$ be a bounded closed convex subset of complete TCS $(X, d, W)$ with properties $(P)$ and $(Q)$ and let $T: K \rightarrow K$ satisfy the following:

(i) $T$ is uniformly locally directionally nonexpansive on $K$;

(ii) $\alpha(T(A))<\alpha(A)$, for all $A \subseteq K$ for which $\alpha(A)>0$;

(iii) $F$ is r.g.i. on $K$.

Then the fixed point set fix (T) of T is nonempty and compact.

Moreover, using Proposition 16 we also get generalizations of some other Kirk and Saliga [2] fixed point results.

Corollary 19. Let $K$ be a bounded closed convex subset of a complete TCS $(X, d, W)$ with properties $(P)$ and $(Q)$ and let $T: K \rightarrow K$ satisfy the following:

(i) $T$ is uniformly locally directionally nonexpansive on $K$;

(ii) $d(T x, T y) \leq \theta(\max \{d(x, T x), d(y, T y)\})$, where $\theta$ : $\mathbb{R}^{+} \rightarrow \mathbb{R}^{+}$is any function for which $\lim _{t \rightarrow 0^{+}} \theta(t)=0$.

Then $T$ has a unique fixed point $x_{0} \in K$ if and only if $F$ is an r.g.i. on $K$.

Proof. Proposition 16 gives $\inf _{K}(F)=0$ and as in [2] one can prove that $\lim _{c \rightarrow 0^{+}} \operatorname{diam}\left(L_{c}\right)=0$. By Theorem $1.2[1], T$ has a unique fixed point if and only if $F$ is r.g.i. on $K$.

Theorem 20. Let $K$ be a bounded closed convex subset of a complete TCS $(X, d, W)$ with properties $(P)$ and $(Q)$ and suppose $T: K \rightarrow K$ satisfies the following:

(i) $T$ is directionally nonexpansive on $K$;

(ii) $\mu\left(T\left(L_{c}\right)\right) \leq k \cdot \mu\left(L_{c}\right)$, for some $k<1$ and all $c>0$;

(iii) $F$ is an r.g.i. on $K$.

Then the fixed point set fix (T) of T is nonempty and compact. Moreover, if $\left\{x_{n}\right\} \subseteq K$ satisfies $\lim _{n \rightarrow \infty} d\left(x_{n}, T x_{n}\right)=0$, then $\lim _{n \rightarrow \infty} d\left(x_{n}\right.$, fix $\left.(T)\right)=0$.

Proof. By Proposition 16, $\inf _{K}(F)=0$. Since (i) implies that

$$
d\left(T x, T^{2} x\right) \leq d(x, T x), \quad \forall x \in K,
$$

the conclusion follows immediately from Theorem 2.3 $[2]$.

We established that $\lim _{n \rightarrow \infty} d\left(x_{n}, T x_{n}\right)=0$ for every sequence $\left\{x_{n}\right\}$ defined by $x_{n}=T_{\alpha} x_{n-1}, n \in \mathbb{N}$, where $x_{0} \in K$ and $\alpha \in(0,1)$. Therefore $\lim _{n \rightarrow \infty} d\left(x_{n}, f \mathrm{xx}(T)\right)=0$ meaning that $\left\{x_{n}\right\}$ converges to the set fix $(T)$, but the convergence to the specific point from $\mathrm{fix}(T)$ is not provided. Putting some additional assumption, we could arrange that the sequence $\left\{x_{n}\right\}$ converges to a fixed point of the mapping $T$.

Next, we recall the concept of weakly quasi-nonexpansive mappings with respect to sequence introduced by Ahmed and Zeyada in [15]. 
Definition 21 (see [15]). Let $(X, d)$ be a metric space and let $\left\{x_{n}\right\}$ be a sequence in $D \subseteq X$. Assume that $T: D \rightarrow X$ is a mapping with fix $(T) \neq \emptyset$ satisfying $\lim _{n \rightarrow \infty} d\left(x_{n}\right.$, fix $\left.(T)\right)=$ 0 . Thus, for a given $\varepsilon>0$ there exists $n_{1}(\varepsilon) \in \mathbb{N}$ such that $d\left(x_{n}, f \mathrm{ix}(T)\right)<\varepsilon$ for all $n \geq n_{1}(\varepsilon)$. Mapping $T$ is called weakly quasi-nonexpansive with respect to $\left\{x_{n}\right\} \subseteq D$ if for each $\varepsilon>0$ there exists $p(\varepsilon) \in \operatorname{fix}(T)$ such that, for all $n \in \mathbb{N}$ with $n \geq$ $n_{1}(\varepsilon), d\left(x_{n}, p(\varepsilon)\right)<\varepsilon$.

The next result is improvement of Theorem 20 and also a generalisation of Theorem 2.24 from [15].

Theorem 22. Let $K$ be a bounded closed convex subset of a complete TCS $(X, d, W)$ with properties $(P)$ and $(Q)$ and let $T: K \rightarrow K$ satisfy the following:

(i) $T$ is directionally nonexpansive on $K$;

(ii) $\alpha\left(T\left(L_{c}\right)\right) \leq k \alpha\left(L_{c}\right)$ for some $k<1$ and all $c>0$;

(iii) $F$ is r.g.i. on $K$;

(iv) $\left\{x_{n}\right\} \subseteq K$ satisfies $\lim _{\lim _{n \rightarrow \infty}} d\left(x_{n}, T x_{n}\right)=0$ and $T$ is weakly quasi-nonexpansive with respect to $\left\{x_{n}\right\}$.

Then $\left\{x_{n}\right\}$ converges to a point in $\operatorname{fix}(T)$.

Proof. Our assertion is a consequence of Theorem 20 and Theorem 2.5(b) from [15].

Using Proposition 16, the next corollary holds.

Corollary 23. Let $K$ be a bounded closed convex subset of a complete TCS $(X, d, W)$ with properties $(P)$ and $(Q)$ and let $T: K \rightarrow K$ satisfy the following:

(i) $T$ is directionally nonexpansive on $K$;

(ii) $\alpha\left(T\left(L_{c}\right)\right) \leq k \alpha\left(L_{c}\right)$ for some $k<1$ and all $c>0$;

(iii) $F$ is r.g.i. on $K$;

(iv) $T$ is weakly quasi-nonexpansive with respect to sequence $x_{n}=T_{\alpha}^{n} x_{0}, n \in \mathbb{N}, x_{0} \in K, \alpha \in(0,1)$.

Then $\left\{x_{n}\right\}$ converges to a point in $\operatorname{fix}(T)$.

\section{Conflict of Interests}

The authors declare that there is no conflict of interests regarding the publication of this paper.

\section{Acknowledgments}

The authors are very grateful to the anonymous referees for their careful reading of the paper and suggestions which have contributed to the improvement of the paper. This paper is partially supported by Ministarstvo nauke i životne sredine Republike Srbije.

\section{References}

[1] M. Angrisani and M. Clavelli, "Synthetic approaches to problems of fixed points in metric space," Annali di Matematica Pura ed Applicata. Serie Quarta, vol. 170, pp. 1-12, 1996.
[2] W. A. Kirk and L. M. Saliga, "Some results on existence and approximation in metric fixed point theory," Journal of Computational and Applied Mathematics, vol. 113, no. 1-2, pp. 141-152, 2000.

[3] O. Hadžić, "Some properties of measures of noncompactness in paranormed spaces," Proceedings of the American Mathematical Society, vol. 102, no. 4, pp. 843-849, 1988.

[4] W. Takahashi, "A convexity in metric space and nonexpansive mappings.I," Kodai Mathematical Seminar Reports, vol. 22, pp. 142-149, 1970.

[5] L. A. Talman, "Fixed points for condensing multifunctions in metric spaces with convex structure," Kodai Mathematical Seminar Reports, vol. 29, no. 1-2, pp. 62-70, 1977.

[6] G. V. R. Babu and G. N. Alemayehu, "Existence of common fixed points via modified Mann iteration in convex metric spaces and an invariant approximation result," Tamkang Journal of Mathematics, vol. 41, no. 4, pp. 335-347, 2010.

[7] L. Gajić, "On convexity in convex metric spaces with application," Journal of Natural \& Physical Sciences, vol. 3, no. 1-2, pp. 39-48, 1989.

[8] L. J. Gajić, "On measure of non-compactness in convex metric spaces," Filomat, vol. 19, pp. 1-5, 2005.

[9] L. Gajić and V. Rakočević, "Quasicontraction nonself-mappings on convex metric spaces and common fixed point theorems," Fixed Point Theory and Applications, no. 3, pp. 365-375, 2005.

[10] L. Gajić and V. Rakočević, "Pair of non-self-mappings and common fixed points," Applied Mathematics and Computation, vol. 187, no. 2, pp. 999-1006, 2007.

[11] M. Moosaei, "Common fixed points for some generalized contraction pairs in convex metric spaces," Fixed Point Theory and Applications, vol. 2014, article 98, 2014.

[12] H. K. Nashine, "Application of fixed point theorem to best simultaneous approximation in convex metric spaces," Kragujevac Journal of Mathematics, vol. 33, pp. 107-118, 2010.

[13] W. Phuengrattana and S. Suantai, "Common fixed points of an infinite family of nonexpansive mappings in uniformly convex metric spaces," Mathematical and Computer Modelling, vol. 57, no. 3-4, pp. 306-310, 2013.

[14] K. Goebel and W. A. Kirk, Topics in Metric Fixed Point Theory, Cambridge University Press, Cambridge, UK, 1990.

[15] M. A. Ahmed and F. M. Zeyada, "Some convergence theorems of a sequence in complete metric spaces and its applications," Fixed Point Theory and Applications, vol. 2010, Article ID 647085, 10 pages, 2010. 


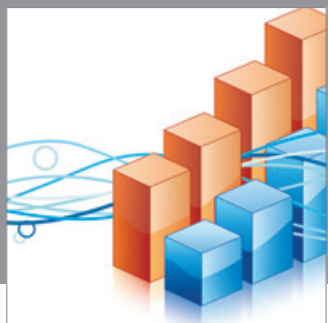

Advances in

Operations Research

mansans

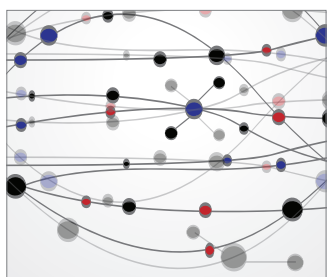

The Scientific World Journal
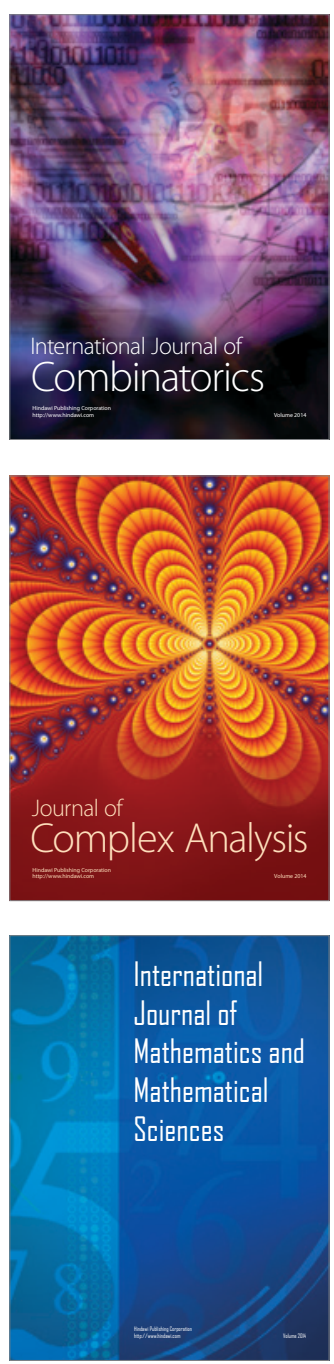
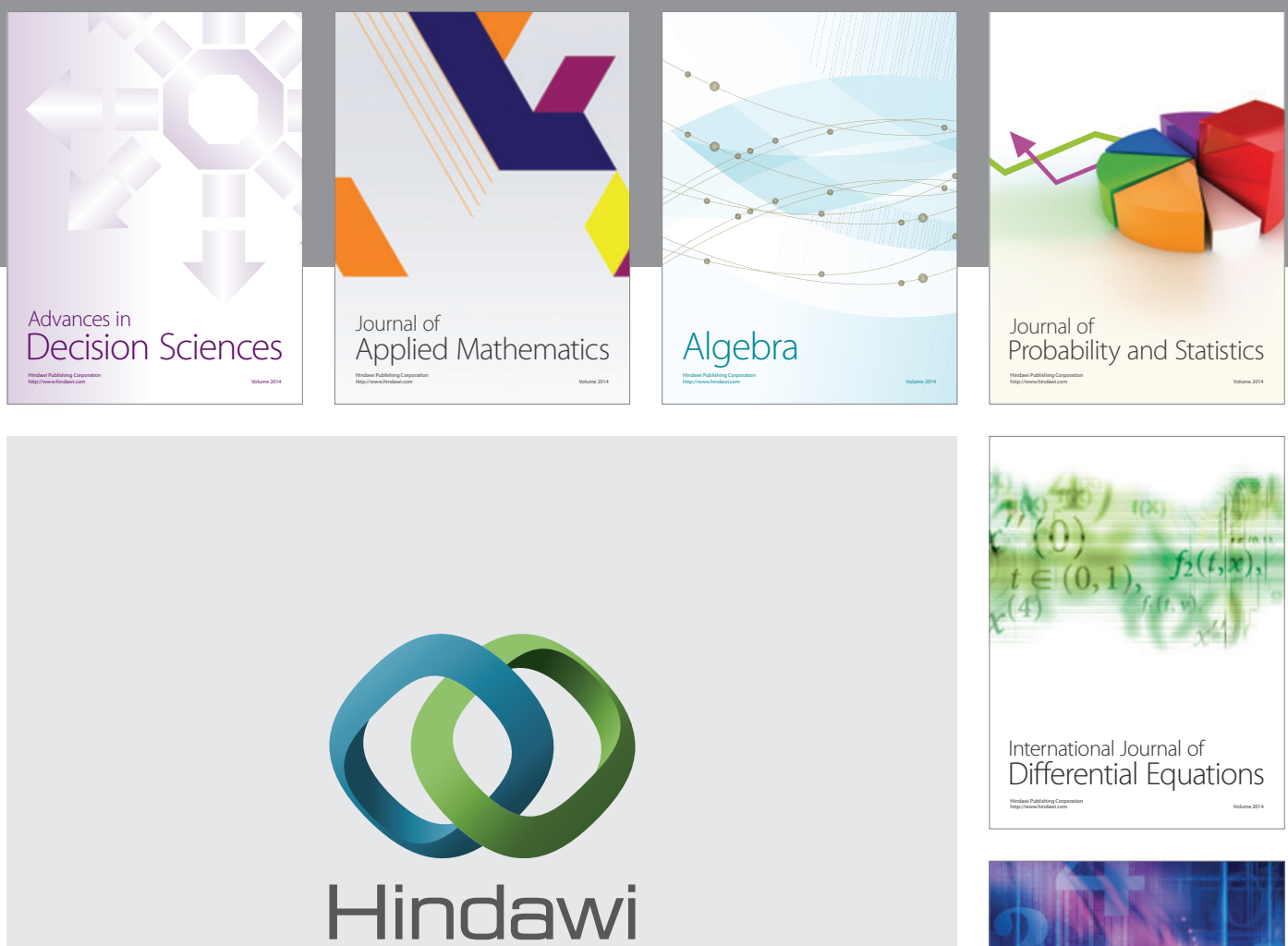

Submit your manuscripts at http://www.hindawi.com
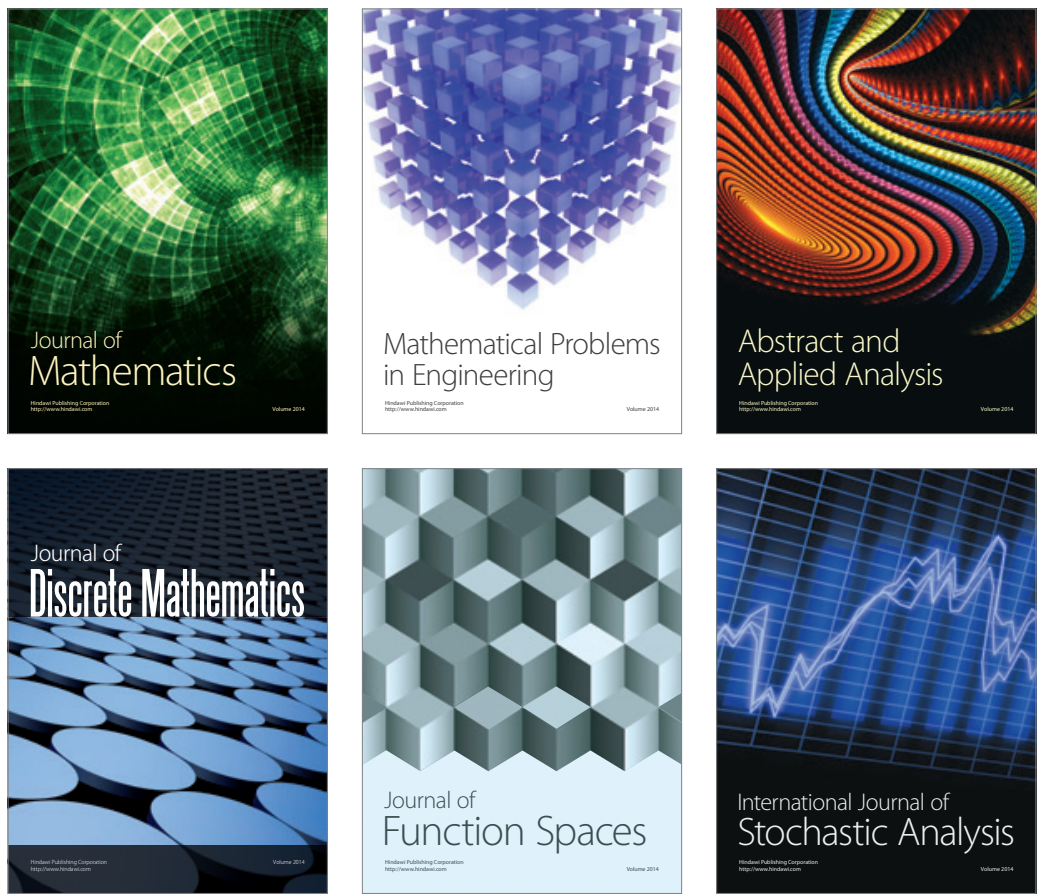

Journal of

Function Spaces

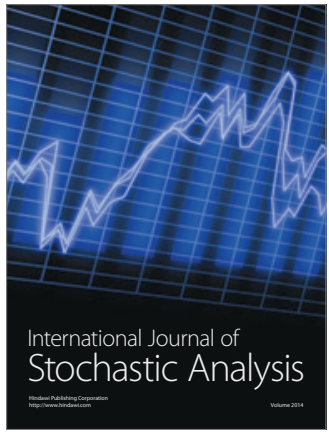

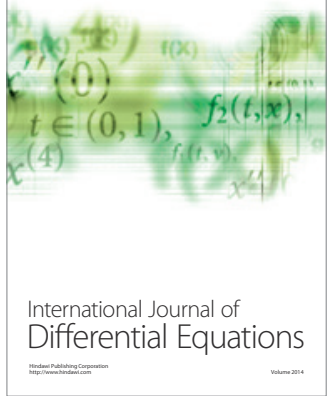
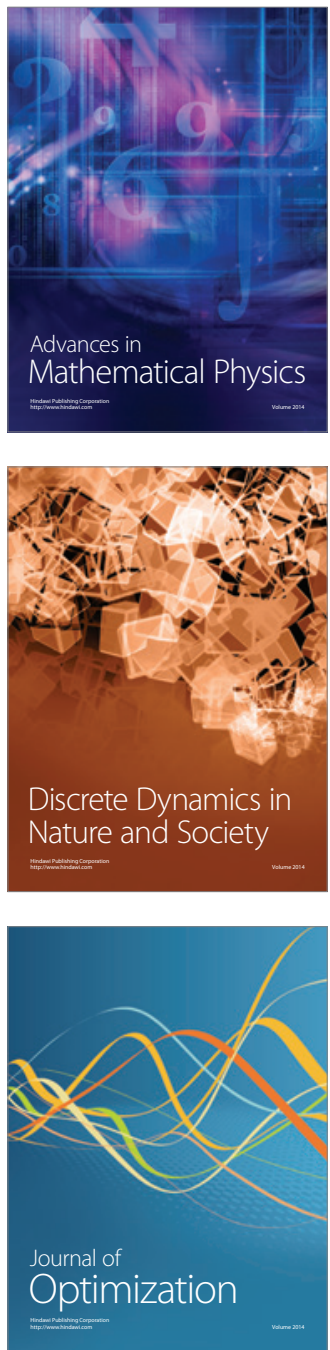